\title{
Evaluation of the Levator Palpebrae Superioris Muscle Plication in the Treatment of Ptosis (About 12 Cases)
}

\author{
Aziz El Ouafi*, Adil Bouzidi, Fatine El Alami, Said Iferkhass, Abdelkader Laktaoui, \\ Mohammed Moumine
}

Ophthalmology Service, Moulay Ismail Military Hospital, Meknes, Morocco

Email: *elouafi.aziz@gmail.com

How to cite this paper: El Ouafi, A., Bouzidi, A., El Alami, F., Iferkhass, S., Laktaoui, A. and Moumine, M. (2019) Evaluation of the Levator Palpebrae Superioris Muscle Plication in the Treatment of Ptosis (About 12 Cases). Open Journal of Ophthalmology, 9, 125-133.

https://doi.org/10.4236/ojoph.2019.93013

Received: March 4, 2019

Accepted: June 14, 2019

Published: June 17, 2019

Copyright $\odot 2019$ by author(s) and Scientific Research Publishing Inc. This work is licensed under the Creative Commons Attribution International License (CC BY 4.0).

http://creativecommons.org/licenses/by/4.0/

\begin{abstract}
Introduction: The ptosis is a fall of the upper eyelid in relation to a deficit of the levator device of this one. In practice, it poses two major problems, the first one is the eminent risk of amblyopia during severe congenital ptosis, and the second is of an aesthetic nature, representing the main reason for consultation. The aim of this work is to evaluate the interest of the levator palpebrae superioris muscle plication in the ptosis surgery. Materials and Methods: We collected 12 patients who received a correction of their ptosis by plication of the levator palpebrae superioris muscle over a period of 3 years from January 2012 to December 2014. Result: The mean age at treatment was 22 years; the ptosis was congenital in 8 cases, and acquired in 4 . The ptosis was major in $67 \%$ and moderate in $33 \%$ of the cases. Muscle plication was the basic surgical technique in all patients in our series. The function and aesthetic results were satisfying in 6 cases (50\%), good in 4 cases (34\%), acceptable in 1 case and bad in 1 case (8\%). Discussion: The comparative study has shown that the plication of the levator palpebrae superioris muscle is a possible alternative for the correction of ptosis whatever the type of ptosis with results comparable to the reference technique compared to the degree of correction, whereas the operative follow-up is simpler and more minor complications. Conclusion: The surgical treatment of ptosis should be done after a systematic clinical examination and after very precise indications. However, the plication of the levator muscle of the upper eyelid has shown its functional and aesthetic efficiency in congenital ptosis and in the ptosis of the adult.
\end{abstract}

\section{Keywords}

Congenital Ptosis, Acquired Ptosis, Placation of the Levator Palpebrae Superioris Muscle 


\section{Introduction}

Ptosis is a disorder of the statics and dynamics of the upper eyelid in relation to a deficit of the levator device thereof. It represents one of the most frequent affections in palpebral pathology posing in practice two major problems: The first is of a functional order related to the eminent risk of amblyopia in the case of major congenital ptosis, the second is of aesthetic order, representing the main reason for consultation. This damage requires a perfect mastery of aesthetic palpebral surgery techniques.

The surgical techniques encountered in the literature all derive from two main types of operations [1] [2]: The resection of the fascia of the levator palpebrae superioris muscle which consists of a monobloc resection of the Muller muscle and the fascial fasciculus of the levator while retaining the tarsus, and the frontal muscle suspension which consists of mooring the upper eyelid to the frontal muscle by an autologous or heterologous material. The postoperative results are very satisfactory if certain rules of palpebral aesthetic surgery are respected; however, the complications related to the surgery are very numerous and can in some cases be dramatic.

We will report through this work the experience of the service of stomatology and maxillofacial surgery of the military hospital Moulay Ismail of Meknes about the treatment of ptosis by a surgical technique (plication of the levator palpebrae soperosis muscle), from a retrospective study of 12 patients over a period of 3 years, from January 2012 to December 2014. The objective of this work is to detail this surgical technique while describing the epidemiological, clinical aspects of our patients and the postoperative results.

\section{Materials and Methods}

Our work is a retrospective study, extending from January 1st, 2012 to December 31st, 2014, for a period of three years. It concerned the patients collected at the department of stomatology and maxillofacial surgery of the Moulay Ismail military hospital of Meknes who have had a correction of their ptosis by the plication of the levator palpebrae superioris muscle.

The exclusion criteria were anterior or concomitant eyelid surgery for another indication.

The collection of patients' data was done using a standardized farm return including: Patient identity and age, personal history, preoperative clinical and para-clinical evaluation, Indication of surgery and postoperative results.

\subsection{Surgical Technique}

Frueh's technique was the standard surgical technique applied in our series, it corresponds to an aponeurosis plication in a plane located between the posterior fascias and the anterior surface of the Müller muscle, hence the term interlamellar plication or interbeam of the levator muscle. It includes the following operating times [2] [3]: 
- Marking of the palpebral fold, of the lateral edges of the cornea and of the pupillary center on the eyelid margin with the dermographic pencil;

- Local anesthesia with alphacaïne (articaïne, epinephrine) in the palpebral fold: 0.5 to $1 \mathrm{~mL}$ suffice;

- Cutaneous incision of 8 to $12 \mathrm{~mm}$ according to the authors, located discreetly under the palpebral fold, about 7 to $8 \mathrm{~mm}$ of the ciliary border;

- Dissection to the upper edge of the tarsus;

- Incision of the fascia: Passage of the foam scissors between the fascia and the tarsus, then in a natural space between the fascia and the posterior face of the Müller muscle;

- Using hooks, pulling on the fascia downwards, then passing the needle of a resorbable thread 5/0 (used in our study) or non-resorbable (monofilament $5 / 0$ ) on the posterior side fascia high enough above the initial incision. The patient is then asked (attenuated lights of the operating light or microscope) to look up and down, in order to observe a wide movement of the suture and to check that the suture is solid;

- Passage of the needle to the upper edge of the tarsus;

- Gradual tightening to adjust contour and height of upper eyelid to limb (attenuated lights or microscope);

- Repair of the palpebral fold and cutaneous suture by two to three points of $6 / 0$ monofilaments.
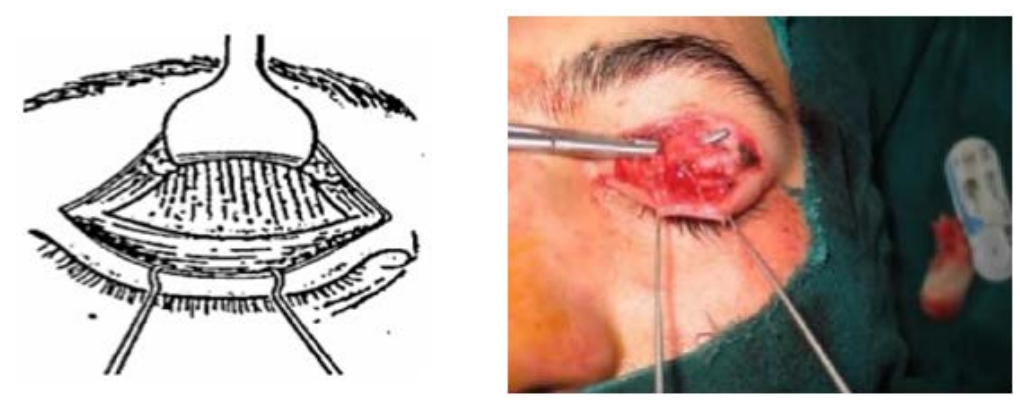

Visualization of the fascia of the levator palpebrae superioris muscle, the orbital septum, and the Whitnall transverse ligament after dissection of the preseptal and pretarsal orbicularis in a 14-year-old child to correct major unilateral congenital ptosis.

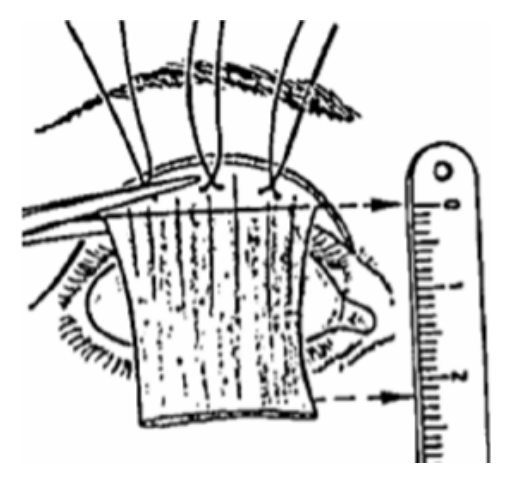


Section of the fascia of the levator palpebrae superioris muscle flush with the tarsus then resection of the fascia according to the degree of ptosis and the function of the levator muscle.

\subsection{Statistical Analysis}

Statistics were performed using Student t-tests, all data were analyzed using SPSS version 20 .

\section{Results}

We recorded 12 patients who received a correction of their ptosis by plication of the levator palpebrae superioris muscle over a period of 3 years, an average frequency of 4 patients/year. The average age of our patients was 22 years with extremities of 08 years and 42 years.

Our series included 5 men and 7 women, a sex-ratio M:F of 0.71 . In this patient group, no cases of bilateral ptosis were noted. All cases treated were unilateral. Most of our selected patients had the ptosis on the right side (9 eyes) (Table 1).

Twelve patients were included in this study, 8 cases of congenital ptosis (66.7\%), and 4 cases of acquired ptosis (33.3\%) distributed as follows: 3 cases had post traumatic ptosis and 1 case neurogenic ptosis (Figure 1 ).

The majority of our patients had severe ptosis (8 patients): $66.6 \%$ of the cases, and 04 patients had moderate ptosis $(33.3 \%)$, minimal ptosis was not found in any case (Figure 2).

The stroke of the levator muscle was less than $4 \mathrm{~mm}$ in 7 cases $(58.3 \%)$, between 4 and $8 \mathrm{~mm}$ in 5 cases (41.6\%). According to the clinical data, it seems very difficult to confirm the existence of a parallelism between the degree of ptosis and the function of the levator muscle, but we can underline the importance of the form associating major ptosis with a poor function of the levator muscle.

Local anesthesia was performed in 11 patients (91\%), whereas general anesthesia was performed in 1 patients (9\%).

All our patients were operated by the same surgical technique, which consists of a plication of the levator muscle by mini incision and hook-up the upper eyelid to the levator muscle, through anterior approach.

Table 1. Characteristics of our patients.

\begin{tabular}{|c|c|}
\hline Characteristics & Percentage \\
\hline Average age & 22 years $(08-42)$ \\
\hline Sex-ratio M:F & 0.71 \\
\hline \multicolumn{2}{|l|}{ Laterality } \\
\hline - Unilateral & $100 \%$ \\
\hline - Bilateral & $0 \%$ \\
\hline \multicolumn{2}{|l|}{ Side } \\
\hline - $\quad$ Right & $75 \%$ \\
\hline - $\quad$ Left & $25 \%$ \\
\hline
\end{tabular}




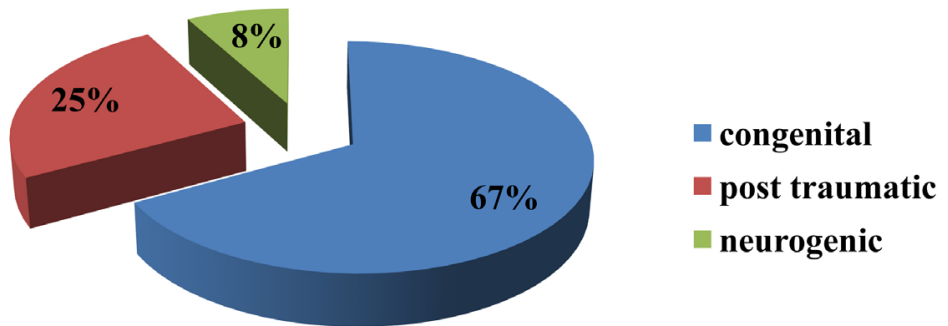

Figure 1. Distribution according to the etiology of ptosis.

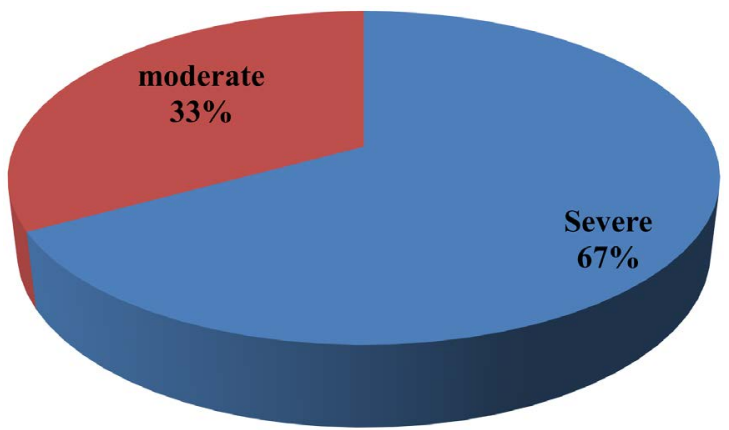

Figure 2. Distribution according to severity of ptosis.

The average postoperative follow-up was 5 months with extremes ranging from 3 months to 1 year. The postoperative period was without problems for all our patients. Our patients stayed in the service 1 day on average, medical treatment (analgesic, corticosteroid, antibiotics, physiological serum) was started in all our patients accompanied by cryotherapy session, local care and removal of the son J6 postoperative. Five of our patients required orthoptic sessions, 10 sessions on average, while the rest settled for self-reeducation sessions.

The postoperative results regardless of the type of ptosis were excellent in 8 cases, good in 3 cases, bad in 1 case (Figure 3 ).

Under-correction was the only complication noted in our study series ( 3 cases), found in one case of congenital ptosis and in two cases of acquired ptosis.

\section{Discussion}

Our comparative work will be based on two retrospective studies: A study done at the ophthalmology department of Dupuytren Hospital of Limoges in France on 119 cases (98 adult senile ptosis and 28 congenital ptosis) over a period of 6 years ranging from January 2003 to August 2009 [3], And a study done at the ophthalmology department of CHU Daisan in Japan involving 45 patients (75 eyelids) operated for senile ptosis over a period of two years from April 14, 2014 to April 14, 2016 [4].

\subsection{Epidemiological Data: (Table 2)}

1) Frequency: In the series of Matsuda et al. [4], 45 patients were operated over a period of 2 years with a frequency of 22 patients/year, while in the series of Robert and Denis [5], 119 patients were operated over a period of 6 years 


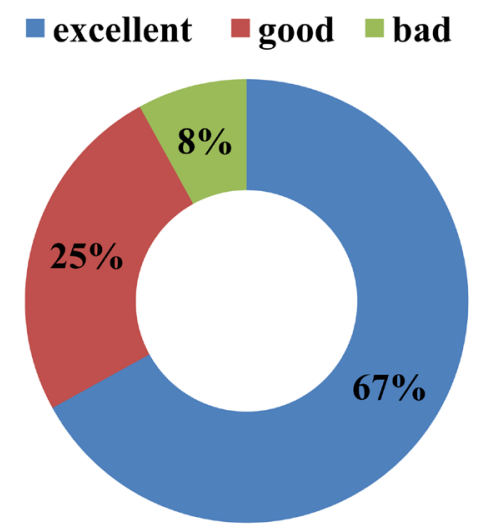

Figure 3. Post operative results.

Table 2. Epidemiological data of the three series.

\begin{tabular}{cccccc}
\hline & $\begin{array}{c}\text { Frequency } \\
\text { per year }\end{array}$ & $\begin{array}{c}\text { Average } \\
\text { age }\end{array}$ & Sex & Laterality & $\begin{array}{c}\text { Affected } \\
\text { side }\end{array}$ \\
\hline Matsuda et al. series & 22 patients/year & 50 & Female: $60 \%$ & Bilateral: $67 \%$ & Right: $50.2 \%$ \\
& & years & Male: $40 \%$ & Unilateral: $33 \%$ & Left: $49.8 \%$ \\
& & 36 & Female: $51 \%$ & Bilateral: $68 \%$ & Right: $48.3 \%$ \\
Robert and Dennis series & 19 patients/year & years & Male: $48 \%$ & Unilateral: $32 \%$ & Left: $51.7 \%$ \\
& & 22 & Female: $58.1 \%$ & Unilateral: $100 \%$ & $\begin{array}{c}\text { Right: } 75 \% \\
\text { Left: } 25 \%\end{array}$ \\
Our series & 4 patients/year & years & Male: $41.9 \%$ & & \\
& & & & &
\end{tabular}

with a frequency of 19 patients/year. In our study, 12 patients were operated for their ptosis over a period of 3 years with a frequency of 4 patients/year. The low frequency in our series is explained by the fact that the treatment of ptosis is done both by the ophthalmology department and by stomatology and maxillofacial surgery department.

2) Age: The average age in the series of Matsuda et al. [4] was 50 years with extremities ranging from 47 years to 87 years, while in the series of Robert and Denis [5], the average age was 36 years with extreme from 2 years to 91 years. In our series, the average age was 22 years [ 8 years -42 years].

3) Sex: In the series of Robert and Denis [3], we do not note any predominance of sex (M:F 49\%) On the other hand, a slight feminine predominance is marked in our study and in the study of Matsuda et al. [4] with a sex ratio M:F of 0.71 and 0.66 respectively.

4) Laterality of the ptosis: The bilateral ptosis was predominant in the Japanese series (67\% of the cases) and in the French series ( $68 \%$ of the cases). It was unilateral in $100 \%$ of the cases in our series.

5) Affected side: The right side was predominant in our study with a percentage of $75 \%$. In the Matsuda series [4] and Robert and Dennis [5] series no significant predominance was noticed.

\subsection{Clinical Data}

1) Type of ptosis: In the Matsuda et al. series all patients had senile ptosis, no 
case of congenital ptosis was described. In the Robert and Denis series, the fascial senile ptosis was the most predominant with a percentage of $90 \%$ contrary to our study where congenital ptosis predominated with a percentage of $75 \%$.

2) The palpebral fissure height and degree of ptosis: The measurement of the palpebral fissure makes possible to specify the degree of ptosis, an important element in the surgical management. The major ptosis is the most frequent in the three series, with a percentage of $70 \%$ in the series of Matsuda et al., $41.7 \%$ in the series of Robin and Denis and $66.6 \%$ in our series.

\subsection{Therapeutic Data}

1) Type of anesthesia: Local anesthesia is the basic anesthesia technique in the three studies except for one case of congenital ptosis in our series for which general anesthesia was used because of the patient's agitation.

2) Surgical Technique: Frueh's technique was the standard surgical technique applied in our series and in the Matsuda et al. series and in 71 patients in Rober and Dennis series.

\section{Post Operative Results: (Table 3 )}

The Frueh technique resulted in a significant increase in palpebral fissure height and levator muscle action in all three series. In the series of Robert and Dennis [5], 67\% of cases obtained an excellent result and 15\% required revision surgery. In the Matsuda et al. [4] series, excellent results were obtained in $70 \%$ of cases. No surgical revision was postponed. In our series, an excellent result was noted in $67 \%$ of patients, a good result in $25 \%$ of cases and only 1 case required surgical revision after 6 months.

Postoperative ocular reeducation is a very important step in the management of ptosis, it allows a quicker visual rehabilitation and a better aesthetic result, provided that it is started as early as possible. Moreover, in our study, the patients who obtained the best results are the patients who have been rehabilitated with a sufficient number of sessions and a specific duration.

Table 3. Functional and aesthetic results according to series.

\begin{tabular}{|c|c|c|c|c|c|c|}
\hline \multirow[t]{2}{*}{ Series } & \multirow[t]{2}{*}{ Location } & \multirow[t]{2}{*}{ Year } & \multirow{2}{*}{$\begin{array}{l}\text { Number of } \\
\text { patients }\end{array}$} & \multicolumn{3}{|c|}{$\begin{array}{l}\text { Functional and } \\
\text { aesthetic results }\end{array}$} \\
\hline & & & & Excellent & Average & $\mathrm{Bad}$ \\
\hline $\begin{array}{l}\text { Robert and } \\
\text { Denis }\end{array}$ & $\begin{array}{c}\text { Dupuytren } \\
\text { Hospital of } \\
\text { Limoges France }\end{array}$ & $\begin{array}{c}\text { January } 2003 \\
\text { to January } \\
2009\end{array}$ & 119 & $67 \%$ & $18 \%$ & $15 \%$ \\
\hline $\begin{array}{c}\text { Matsuda et } \\
\text { al. }\end{array}$ & $\begin{array}{l}\text { CHU Daisan } \\
\text { Japan }\end{array}$ & $\begin{array}{l}\text { April } 2014 \text { to } \\
\text { april } 2016\end{array}$ & 45 & $70.2 \%$ & $21.8 \%$ & $8 \%$ \\
\hline Our series & HMMI Meknes & $\begin{array}{c}\text { January } 2012 \\
\text { to January } \\
2014\end{array}$ & 12 & $67 \%$ & $25 \%$ & $8 \%$ \\
\hline
\end{tabular}




\subsection{Post-Operative Complications}

1) Under-correction: Except the frank form where it is necessary to intervene in the same week, it is preferable to wait 06 months before asserting the hypocorrection; this is related, either with incorrect preoperative indications or intraoperative destruction of a fragile levator, or finally skidding sutures [6]. This is indeed the only complication we encountered in our series with a percentage of $25 \%$ of operated cases (3 eyelids), against $29.3 \%$ in the series of Matsuda et al.

2) Over-correction: This is a complication of the wide resection of the reliever; it is exceptional with frontal suspension methods. Some hypercorrections are minor and will disappear within a few days, either spontaneously, or favored by maneuvers such as: Massage, traction of the upper eyelid downwards, loosening of the overlock in case of Müller-conjunctive monobloc resection. In the case of a true persistent retraction, a surgical revision is essential; the therapeutic method is directly depending on the size of the retraction and the type of intervention [6]. No cases of over-correction were noted in the three series.

3) The eyelid margin malpositions:

${ }^{*}$ Ectropion: It is favored by a cutaneous docking too high on the levator or the tarsus, and/or a cut resection too important.

${ }^{\star}$ Entropion: Entropion is related to extensive conjunctival resection and/or lack of fold formation. That is why many authors [7] insist on the arrangement of the two palpebral incisions which must not be too far apart to avoid deformations of the eyelid margin.

4) Infection: It is rare. After resection, it can sit at the level of the sutures in the palpebral fold, hence the need to disinfect the palpebral fold by lifting the cutaneous fold. Infection is more common after suspension: Suspended methods that expose to infections are mainly those involving the use of an inert material strap with tarsal mooring that connects the Meibomian glands with the palpebral tissues [6]. These infections are accompanied or not by granulomas and can occur very late. They often require the removal of the strap. It is then quite remarkable to note that ptosis does not necessarily re-offend. No cases of infection were described in the three series.

\section{Conclusions}

Ptosis is one of the most common affections in eyelid pathology. It requires careful clinical examination with precise measurements of both ptosis and levator function of the upper eyelid. These clinical elements will eventually guide the etiological diagnosis, and also to consider an appropriate surgical protocol. This study relating the experience of the department of stomatology and maxillofacial surgery of the military hospital Moulay Ismail of Meknes in the management of ptosis allowed us to focus on some important elements: The importance of the severe form of the ptosis, combining a major ptosis with poor function of the levator muscle requiring a special and conservative management. The plication of 
the levator muscle remains the technique of choice in the therapeutic management of adult and congenital ptosis. It has comparable efficiency to the reference technique (conventional anterior technique) with reduced postoperative morbidity and long-term satisfactory results. Its minimally invasive character does not significantly affect the anatomical integrity of the upper eyelid, moreover, it is faster than the conventional technique by anterior way and makes possible to obtain a better aspect of the contour of the upper eyelid.

The early postoperative ocular reeducation is necessary to obtain better results. Our study thus confirms the importance and validity of this surgical technique for the management of children and adult's ptosis.

\section{Conflicts of Interest}

The authors declare no conflicts of interest regarding the publication of this paper.

\section{References}

[1] Longueville, E. (2009) Ptosis Surgical Techniques. Journées de Réflexions Ophtalmologiques, 14, 489-494.

[2] Frueh, B.R., Musch, D.C. and McDonald, H.M. (2004) Efficacy and Efficiency of a Small-Incision, Minimal Dissection Procedure versus a Traditional Approach for Correcting Aponeurotic Ptosis. Ophthalmology, 111, 2158-2163.

https://doi.org/10.1016/j.ophtha.2004.07.019

[3] Frueh, B.R., Musch, D.C. and McDonald, H. (2004) Efficacy and Efficiency of a New Involutional Ptosis Correction Procedure Compared to a Traditional Aponeurotic Approach. Transactions of the American Ophthalmological Society, 102, 199-206.

[4] Matsuda, H., Shiba, T., Takahashi, Y. and Tsuneoka, H. (2018) Transcutaneous Aponeurotic Repair with Small Detachment of the Levatoraponeurosis for Aponeurotic Blepharoptosisin Japanese Patients. Journal of Plastic, Reconstructive \& Aesthetic Surgery, 71, 425-430.

[5] Gire, J., Robert, P.-Y., Denis, D. and Adenis, J.-P. (2011) Small-Incision, Minimal Dissection Procedure (Frueh's Procedure) in Correction of Involutional and Congenital Ptosis: A Retrospective Study of 119 Cases. Journal Français D'Ophtalmologie, 34, 439-447.

[6] Morax, S. and Herdan, M.L. (1991) Temporalis Fascia Suspension in the Treatment of Ptosis. The International Journal on Orbital Disorders, Oculoplastic and Lacrimal Surgery, 10, 18 p. https://doi.org/10.3109/01676839109087664

[7] Nerge, L. and Lenoff, C.I. (1972) Interest of the Ohashi Technique in Ptosis Surgery. Clinical Ophthalmology, 2, 129-133. 